\title{
Изучение сорбционных свойств карбоксилированных углеродных нанотрубок на пьезомикровесах ОАВ-типа
}

\author{
(C) 2021 Кучменко Т.А. ${ }^{1}$, Умарханов Р.У. ${ }^{1,2}$, Корнехо Туэрос Х.В. ${ }^{3}$ \\ ${ }^{1}$ Воронежский государственный университет инженерных технологий, Воронеж \\ ${ }^{2}$ ООО «Сенсорика - Новые Технологии», Воронеж \\ ${ }^{3}$ Universidad Continental, Huancayo, Peru \\ Поступила в редакцию 1.03.2021 г.
}

DOI: $10.17308 /$ sorpchrom.2021.21/3467

Рассмотрены особенности сорбции паров индивидуальных легколетучих органических соединений различных классов на фазах карбоксилированных углеродных нанотрубок (МУНТ-соон). Особенность исследования заключается в применении сорбционной фазы малых масс (от 1 до 5 мкг) и прямом взвешивания адсорбатов паров веществ в любой момент сорбции высокочувствительными пьезовесами с чувствительностью до $10^{-12}$ г. Установлена зависимость эффективности сорбции фазой из МУНТ -сон к парам выбранных соединений (спирты, кетоны, кислоты, арены) от массы наносимой фазы на ограниченную площадь поверхности. Такой подход формирования слоя трубок позволяет получить разную по структуре поверхность и пористость, что определяет избирательность сорбции паров. Представлены расчеты изотерм сорбции соединений, позволяющие либо высокоселективно зафиксировать их в смеси, либо оценить изменение концентрации. Установлено, что для одного и того же сорбтива форма изотермы сорбции на фазах разных масс меняется от линейной до S-образной. В связи с этим невозможно описать кривые одной теорией. Установлена максимальная емкость монослоя к молекулам ацетона, минимальная - к парам фенола. Карбоксилированные нанотрубки по-разному сорбируют алифатические спиртов нормального и изомерного строения, выделяются по особенности сорбции бутиловые и

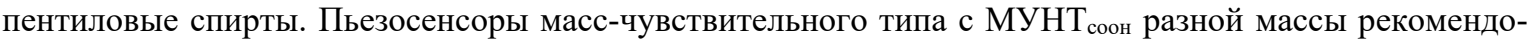
ваны в качестве измерительных элементов для газоанализаторов и систем для интегральной оценки сложных смесей соединений малых концентраций с методологией «электронный нос». Применение в одном массиве сенсоров с фазами МУНТ соон повышает избирательность детектирования компонентов в смеси на уровне микроконцентраций без разделения.

Ключевые слова: сорбция, углеродные нанотрубки, органические биомолекулы, сенсоры, электронный нос, анализ, микроконцентрации.

\section{Введение}

На сегодняшний день в мире только для экологического мониторинга разработан большой парк устройств: от одноканальных, многоканальных газоанализаторов, анализаторов газов с искусственным интеллектом до портативных хроматографов. Газоанализаторы различаются по свойствам и назначению. Однако во всех этих устройствах для определения малых концентраций необходима дополнительная стадия предконцентрирования, но даже при этом невозможен комплексный анализ смеси газов.

При многообразии газоанализаторов, датчиков и тест-систем в России пока невозможна общая оценка и измерение такой характеристики, как запах. Практически всегда при выезде контролирующих лабораторий по жалобам населения не устанавливается причина, природа запаха имеющимися газоанализаторами и тест- 
системами. Именно отсутствие средств комплексной оценки запаха не позволяет ввести этот экологический критерий во многих странах, в том числе и в России. Неприятные запахи контролируются только в 6 странах: Япония, США, Австралия, Франция, Нидерланды, Германия, где приняты допустимые концентрации неприятного запаха [1]. В настоящее время в России работы в этом направлении существенно продвинулись в области разработки нормативной документации.

Комплексную оценку запаха могут дать аналитические системы «электронные носы». В настоящее время известно много производителей «электронных носов», которые предназначены для решения различных задач: Alpha MOS (Франция), Airsense (Германия), ExxonMobil (США), Electronic Sensor Technology (США), Alpha MOS (Франция), The eNose Company (Нидерланды), PerkinElmer (США), Direct Industry (США) и другие. Измерительными элементами в «электронных носах» и газоанализаторах являются полупроводниковые сенсоры и пьезокварцевые микровесы на объемных и поверхностных акустических волнах. Они делятся на 2 группы: 1 группа - характеризуются большим временем жизни и минимальной чувствительностью, селективностью; 2 группа - коротким временем жизни и высокой чувствительностью, селективностью [2]. В настоящее время для решения проблем обеспечения надежности, качества и для создания высокочувствительных газовых сенсоров наиболее перспективным материалом являются наноструктуры [3]. Благодаря своим свойствам: открытой пористости и достаточно узкому распределению пор по размерам, наноматериалы характеризуются хорошими сорбционными свойствами, существенно отличающих их от объемных аналогов [4].

В масс-чувствительных сенсорах преобразователем является пьезокристалл (пьезокварц), как правило, ОАВ-типа с высокой базовой частотой (от 10 МГц) колебаний кварца. В процессе сорбции определяемого вещества на полимерном, вязком, твердом модификаторе, который нанесен на электроды пьезоэлемента, изменяется масса и, как следствие, частота колебаний резонатора [2].

\section{Теоретическая часть}

На данный момент актуальной остается задача создания газовых сенсоров на основе наноструктурированных материалов $[3,4,7]$. Существует много разработок, в основе которых лежит применение углеродных нанотрубок (УНТ) [5, 6, 810], способных улавливать различные газы, в основном легкие, например, $\mathrm{NH}_{3}$, $\mathrm{CO}_{2}, \mathrm{~N}_{2}, \mathrm{O}_{2}, \mathrm{He}$. Главным недостатком УНТ является их окисляемость в кислородсодержащей атмосфере в случае больших значений тока ионизации. В результате, устройства, которые основаны на УНТ быстро становятся негодными. В то же время окисление УНТ является дополнительным фактором их модифицирования, изменения сорбционных свойств и повышения стабильности.

Наряду с проблемами экологического мониторинга активно развивается сенсорный анализ живых систем: пищевых объектов, биопроб [11]. Состояние этих систем оценивают по многим показателям, в том числе по наличию/отсутствию, содержанию нативных летучих биомолекул. К широко распространенным биомолекулам относятся алифатические спирты, кетоны, кислоты, амины, вода, алканы. Для разработки комплексных систем искусственного обоняния на основе массива пьезосенсоров, а также современных интеллектуальных систем для мониторинга над биопробами любой природы, в том числе, без отбора, необходимо изучение сорбционных свойств перспективных модификаторов сенсоров к парам основных биомолекул, которые существенно уступают по полярности исследованиям сорбции легких неорганических газов, но значительно превосходят их по важности контроля в «живых» системах. 
Цель работы - изучить сорбционные свойства микрофаз на основе карбоксилированных многослойных углеродных нанотрубок по отношению к легколетучим органическим соединениям разных классов и оценить перспективность их применения для разработки высокочувствительных пьезосенсоров и анализа сложных смесей.

\section{Экспериментальная часть}

Сорбцию паров органических соединения изучали на многоканальных нановесах «MCNanoW-PQ» (OOO «Сенсорика - Новые Технологии», Россия) с 8-мью рабочими каналами. Для изготовления пьезосенсоров применяли пьезокварцевые резонаторы (ПКР) с базовой частотой колебания 10.0-14.0 МГц. Многоканальные нановесы связаны с программным обеспечением «MCW-Soft», позволяющем регистрировать изменения массы, прикрепленной к электродам фазы в режиме реального времени с шагом 1 с и чувствительностью до 2 нг.

Многоканальные нановесы оснащены герметичной ячейкой из фторопласта объемом $60.0 \mathrm{~cm}^{3}$ с крышкой и патрубками для ввода паров как индивидуальных соединений, так и их смесей в разных режимах - фронтальном, инжекторном $[2,12]$. Сорбцию проводили при температуре $20 \pm 1^{\circ} \mathrm{C}$.

Общая схема измерения массы сорбата легколетучих соединений заключалась в следующем: пробу индивидуального вещества объемом $5.0 \mathrm{~cm}^{3}$ помещали в стеклянный герметичный сосуд, который закрывали мягкой полимерной мембраной и выдерживали 20-30 мин при температуре $20 \pm 1^{\circ} \mathrm{C}$ до установления равновесия в системе «жидкость - пар». После установления равновесия отбирали определенный объем $\left(V_{P Г \Phi}, \mathrm{cm}^{3}\right)$ равновесной газовой фазы (РГФ) каждого вещества индивидуальным шприцем и вводили в ячейку со скоростью $1 \mathrm{~cm}^{3} /$ сек. Массовую концентрацию паров веществ в ячейке детектирования $\left(c, \Gamma / \mathrm{M}^{3}\right)$ изменяли, варьируя объем РГФ от 0.5 до $5.0 \mathrm{~cm}^{3}$ шагом
$0.5 \mathrm{~cm}^{3}$. Каждая точка воспроизводилась не менее 5-7 раз для повышения метрологической надежности расчетов. После проверки стабильности системы и запуска старта измерения пары напускали в околосенсорное пространство. Они сорбируются на фазе из МУНТ-соон, что приводит к изменению частоты колебаний пьезосенсора (рис. 1а). После установлению равновесия в системе открывали патрубок ячейки, при этом начиналась самопроизвольная десорбция (рис.1a).

Для увеличения скорости исследования и повышения уровня постоянства условий сорбцию паров проводили одновременно на 8-ми пьезовесах с фазойМУНТ_-соон, окисленных горячей азотной кислотой (Институт ОЧМ, Черноголовка [5]), определенной массы на электродах ПКР одной партии. Фазы МУНТ-СоОН наносили на обезжиренные электроды ПКР методом «намакивания» в суспензию трубок в толуоле, стабилизированную ультразвуком. Массу варьировали изменением времени экспозиции ПКР в суспензии от 1 до 5 мкг.

Аналитическая информация многоканальных нановесов на основе пьезосенсоров представлена в виде хроночастотограмм (рис. 1a); «визуальных отпечатков» максимальных сигналов пьезосенсоров (рис. 1б) [2].

Для расчета параметров сорбции применяли количественный сигнал пьезовесов с сорбентом - максимальное изменение частоты колебаний пьезосенсора $\left(-\Delta F_{\max }, \Gamma ц\right)$, характеризующее эффективность сорбции органических соединений на фазах сорбента, пропорционально массе сорбата в состоянии равновесия или при прерванной сорбции (псевдоравновесие). В принятом приближении и модели Зауэрбрея $[2,11]$ этот отклик прямо пропорционален массе сорбтива на электродах пьезосенсора в любой момент времени эксперимента. 

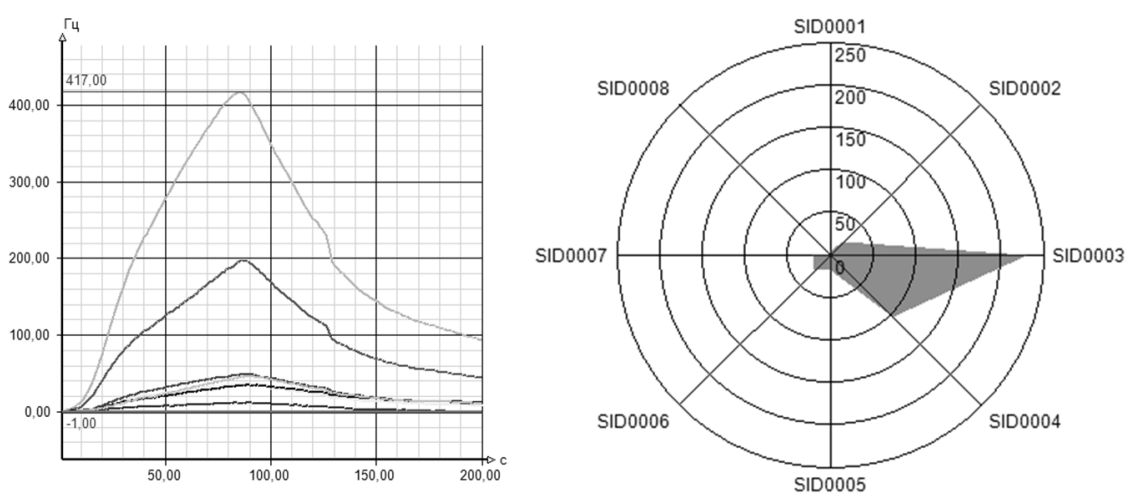

Рис. 1. Регистрируемая информация массива пьезосенсоров в парах веществ (для примера): хроночастотограммы $(a)$, «визуальный отпечаток» максимальных сигналов сенсоров (б). SID001-008 - порядковые номера гнезд, куда устанавливаются пьезовесы с фазой МУНТ-соон разной массы.

Fig. 1. Recorded information of an array of piezosensors in vapours of substances (for example): chrono-frequency diagrams (a), "visual imprint" of the maximum sensor signals

(b). SID001-008 - serial numbers of sockets where piezo balances with MWNT-соон phase of different masses were installed

Применяли препараты индивидуальных соединений, квалификации «чда» (ООО «Реахим», Россия): спирты алифатические $\mathrm{C}_{2}-\mathrm{C}_{5}$, нормального и изомерного строения; кетоны (ацетон, метилэтилкетон, МЭК), арены (бензол, толуол, фенол), амины (метиламин, диэтиламин), кислоты алифатическиеС $\mathrm{C}_{2}, \mathrm{C}_{4}$, $\mathrm{C}_{5}$; хлороформ, алкил ацетаты $\mathrm{C}_{2}-\mathrm{C}_{5}$, ацетальдегид. В качестве основного мешающего вещества применяли воду (бидистиллят с контролем чистоты по электропроводности).

\section{Обсуждение результатов}

Для обоснования и объяснения зависимости сорбционных свойств МУНТ-СоОН от массы слоя на электродах пьезовесов в ЦКП ФГБОУ ВО ЛГТУ (Липецк) на атомно-силовом микроскопе «Solver P447-PRO» с системой видеонаблюдения была исследована микроструктура поверхности фаз МУНТ-соон (рис. 2).

По полученным изображениям рассчитаны средний диаметр зерен и шероховатость поверхностей фаз (табл. 1).

Установлено, что для МУНТ-соОн с увеличением массы фазы на серебряных электродах диаметром 5 мм средний диаметр зерен уменьшается, а шероховатость увеличивается, т.е. при разной массе фазы формируется поверхность разной пористости, что и определяет сорбционные свойства покрытий.

В идентичных условиях получены и изучены изотермы сорбции паров выбранных веществ на фазах МУНТ-соон разной массы (рис. 3).

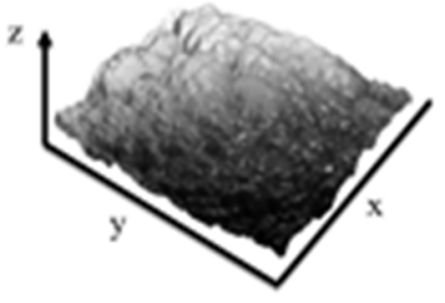

$\mathrm{a}$

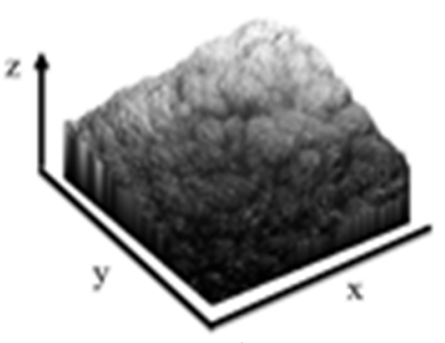

6

Разрешение: 30x30 мкм

Рис. 2. 3D-изображение фаз МУНТ-соон: а) $\mathrm{m}=2.0$ мкг; б) $\mathrm{m}=5,0$ мкг.

Fig.2. 3D image of $\mathrm{MWNT}_{\text {-соон }}$ phases: a) $\mathrm{m}=2.0 \mu \mathrm{g}$; b) $\mathrm{m}=5.0 \mu \mathrm{g}$. 
Таблица 1. Характеристики покрытия МУНТ-соон различных масс (единичная партия) Table 2. Characteristics of the linear correlation of the sorption of vapours of organic compounds on $\mathrm{MWNT}_{\text {-соoн }}$ phases of different masses

\begin{tabular}{|c|c|c|}
\hline $\begin{array}{c}\text { Масса покрытий/ } \\
\text { сорбент }\end{array}$ & $\begin{array}{c}\text { Средний диаметр зерен } \\
\mathrm{d}_{\mathrm{cp}}, \mathrm{HM}\end{array}$ & $\begin{array}{c}\text { Шероховатость } \\
\mathrm{S}_{\mathrm{q}, \mathrm{HM}}\end{array}$ \\
\hline 2.0 & $340 \pm 10$ & 155 \\
\hline 5.0 & $120 \pm 20$ & 630 \\
\hline
\end{tabular}

При описании изотерм сорбции уста- описать кривые одной теорией. Линейновлено, что для одного и того же сорб- ные изотермы описываются уравнением тива форма изотермы сорбции на фазах Генри, коэффициенты уравнений приверазных масс меняется от линейной до S- дены в таблице 2.Уравнение применяется образной. В связи с этим невозможно
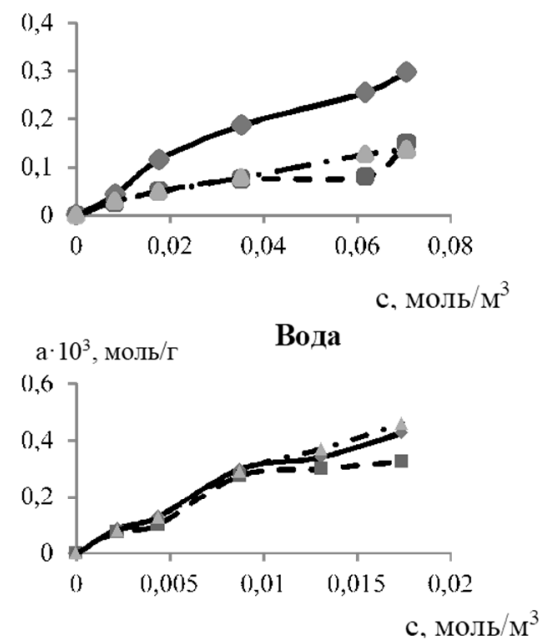

Бутанол-1

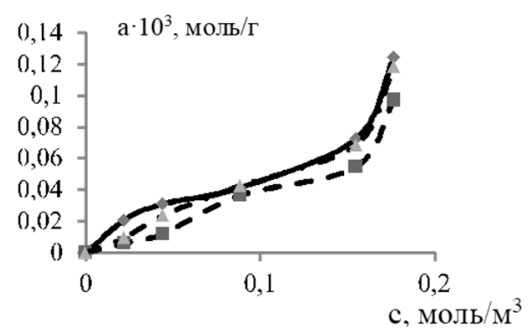

Этанол

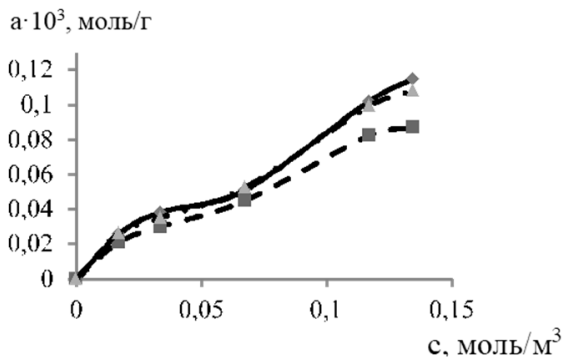

Пропанол-2
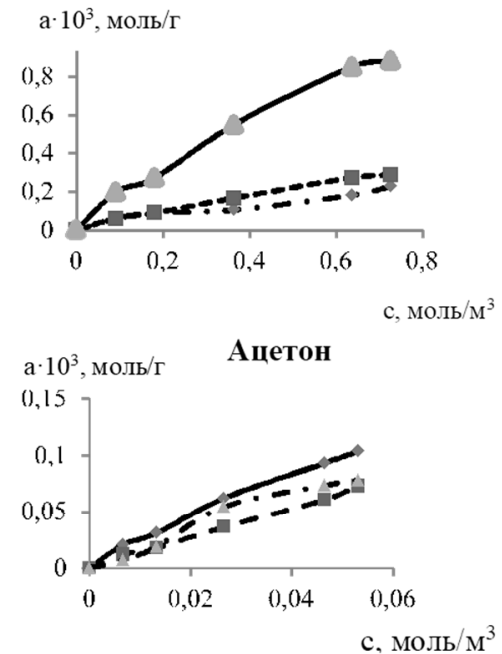

Бутанол-2

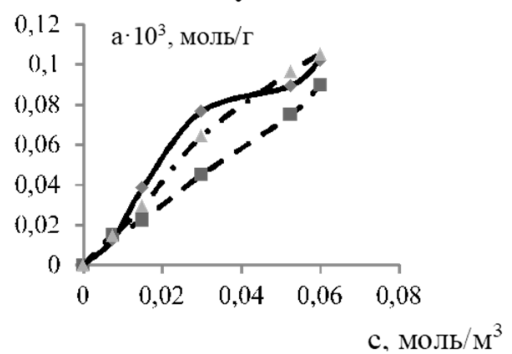

Пропанол-1

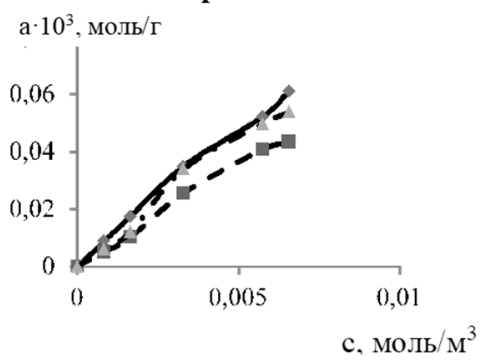

Пентанол-1

Рис. 3. Изотермы сорбции паров выбранных веществ на фазах МУНТ -соон разной массы: маркер ромб - масса фазы 1.2 мкг; треугольник -2.0 мкг; квадрат - 5.0 мкг.

Fig. 3. Isotherms of sorption of vapours of the selected substances on $\mathrm{tMWNT}_{\text {-соон }}$ phases of different masses: rhombus - phase mass $1.2 \mu \mathrm{g}$; triangle $-2.0 \mu \mathrm{g}$; square $-5.0 \mu \mathrm{g}$. 
Таблица 2. Характеристики линейной корреляции сорбции паров органических соединений на фазах МУНТ-соон разных масс

Table 2. Characteristics of the linear correlation of the sorption of vapours of organic compounds on MWNT-cooн phases of different masses

\begin{tabular}{|c|c|c|c|}
\hline \multirow{2}{*}{ Сорбтивы } & $\begin{array}{c}\text { Масса фазы } \\
\text { m, мкг }\end{array}$ & $\begin{array}{c}\text { Коэффициент уравне- } \\
\text { ния, } K_{a}\end{array}$ & $\begin{array}{c}\text { Коэффициент } \\
\mathrm{R}^{2}\end{array}$ \\
\hline \multirow{2}{*}{ Вода } & 1.2 & 4.38 & 0.96 \\
& 5.0 & 2.04 & 0.97 \\
\hline \multirow{2}{*}{ Ацетон } & 2.0 & 0.42 & 0.98 \\
& 5.0 & 1.30 & 0.97 \\
\hline \multirow{2}{*}{ Пропанол-1 } & 2.0 & 1.48 & 0.99 \\
& 5.0 & 1.83 & 0.98 \\
\hline \multirow{2}{*}{ Пропанол-2 } & 1.2 & 0.86 & 0.98 \\
& 2.0 & 0.70 & 0.97 \\
\multirow{2}{*}{ Бутанол-1 } & 5.0 & 0.82 & 0.97 \\
\hline \multirow{2}{*}{ Бутанол-2 } & 1.2 & 26.5 & 0.96 \\
& 5.0 & 28.0 & 0.98 \\
\hline \multirow{2}{*}{ Пентанол-1 } & 1.2 & 2.03 & 0.98 \\
& 2.0 & 1.35 & 0.99 \\
\hline \multirow{2}{*}{ Бензол } & 1.2 & 9.40 & 0.99 \\
& 2.0 & 6.91 & 0.99 \\
& 5.0 & 8.57 & 0.98 \\
\hline \multirow{2}{*}{ Диэтиламин } & 1.2 & 0.36 & 0.94 \\
& 2.0 & 0.19 & 0.98 \\
& 5.0 & 0.13 & 0.97 \\
\hline
\end{tabular}

при минимальных заполнениях поверхности при малых давлениях, в случае, когда газ можно рассматривать, как идеальный. Величина адсорбции отнесена к единице поверхности, а коэффициент пропорциональности КА, называемый константой Генри, формально можно рассматривать как условную константу термодинамического равновесия. Для решения задач аналитической химии эта величина отражает для нановесов чувствительность микровзвешивания паров выбранных веществ.

Установлено, что значения коэффициента $K_{a}$ зависят от массы фазы сорбента для паров воды, ацетона, бензола, в то время как для других соединений в пределах погрешности величины не различимы или меняются незначительно. Значения коэффициента аппроксимации линейной функции практически во всех системах больше/равны 0.97, что позволяет рекомендовать ПКР с фазами карбоксилированных многослойный углеродных нанотрубок в качестве газовых сенсоров для полуколичественной оценки содержания выбранных паров или их смесей либо изменений их концентраций в смесях.

Проследим изменения значений коэффициента $K_{a}$ для гомологического ряда спиртов $\mathrm{C}_{2} \mathrm{H}_{5} \mathrm{OH}-\mathrm{C}_{5} \mathrm{H}_{11} \mathrm{OH}$. При увеличении числа атомов углерода в радикале коэффициент увеличивается при сорбции на фазе МУНТ-соон, т.е. увеличивается распределение вещества в адсорбционном слое, по отношению к его содержанию в объемной фазе и лучше проходит процесс сорбции. Это происходит за счет сил индукционных и водородных взаимодействий с каркасом трубок и карбоксильных групп на концах.

Для фазы сорбента малых масс (1 мкг) чувствительность микровзвешивания паров веществ снижается в ряду: бутанол$1>$ пентанол- $1>$ вода $>$ бутанол- $2>$ пропанол-1 $>$ пропанол- $2>$ ацетон $>$ бензол. 
Таблица 3. Константы уравнения теории БЭТ сорбции паров органических соединений на фазах MУНТ $_{-\mathrm{COOH}}$

Table 3. Constants of the equation of the BET theory of sorption of vapours of organic compounds on $\mathrm{MWNT}_{\text {-соон }}$ phases

\begin{tabular}{|c|c|c|c|}
\hline Сорбтивы & Масса пленки т, мкг & $\begin{array}{c}\text { Емкость монослоя, } \\
a_{m, ~} \text { моль/ }\end{array}$ & $\begin{array}{c}\text { Константа } \\
C_{\text {БЭт }}\end{array}$ \\
\hline Вода & 2.0 & 0.13 & 33.7 \\
\hline Бутанол-1 & 1.2 & 1.4 & 23.1 \\
\hline Бутанол-2 & 5.0 & 0.05 & 7.59 \\
\hline Этанол & 1.2 & 0.15 & 6.20 \\
& 2.0 & 0.16 & 1.70 \\
& 5.0 & 1.2 & 0.41 \\
\hline Пропанол-1 & 1.2 & 0.40 & 2.41 \\
\hline Ацетон & 1.2 & 25 & 6,40 \\
\hline ДЭА & 5.0 & 0.06 & 0.70 \\
\hline Фенол & 2.0 & 0.03 & 1114 \\
& 5.0 & 0.01 & 6662 \\
\hline Хлороформ & 1.2 & 0.49 & 1.33 \\
\hline
\end{tabular}

В этом ряду просматривается закономерность, позволяющая говорить о значительном вкладе в эффект взаимодействия с сорбентом алкильных неразветвленных радикалов с меньшей полярностью, однако исключать влияние водородных связей с ОН-группами нельзя, хотя вклад этих видов взаимодействия меньше.

Для фаз сорбента больших масс (4-5 мкг) эффективность микровзвешивания снижается в ряду:бутанол-1> пентанол- $1>$ вода $>$ пропанол- $1>$ ацетон $>$ бутанол-2 $>$ пропанол- $2>$ бензол.

Ряды чувствительности и сродства для фаз карбоксилированных МУНТ практически идентичны для малых и больших масс. Это подтверждает участие в сорбции не только основных химических центров сорбции, но и пор, каналов, шероховатости поверхности фаз МУНТ-соон.

Сравним $K_{A}$ в уравнениях линейных изотерм сорбции на фазах МУНТ-соонмалой (2.0 мкг) и большой (5.0 мкг) масс для ароматического соединения без активной группы в кольце (бензол) и линейного алифатического с активной ОН-группой (бутанол-1) (табл. 2). Вещества выбраны с наибольшим (бутанол-1) и наименьшим (бензол) сродством к фазе МУНТ. Для бутанола-1 при увеличении массы фазы
МУНТ-соон константа Генри незначительно увеличивается. Для бензола наблюдается обратная зависимость. Чувствительность покрытия МУНТ-соОн мало зависит от массы, а определяется только природой сорбтива.

Процесс адсорбции во многих случаях не ограничивается образованием монослоя и уже при сравнительно низких значениях концентрации c/ $\mathrm{c}_{\mathrm{s}}>0.1$ образуются, как правило, полимолекулярные слои. Такие изотермы адсорбции описываются теорией БЭТ. Константы уравнения по теории БЭТ представлены в таблице 3.

В гомологическом ряду спиртов $\mathrm{C}_{2} \mathrm{H}_{5} \mathrm{OH}-\mathrm{C}_{5} \mathrm{H}_{11} \mathrm{OH}$ при сорбции на фазах МУНТ-соон наблюдается увеличение $a_{m}$, т.е увеличивается число активных центров, которое приходится на единицу массы адсорбента и за счет этого повышается эффективность сорбции. На основании полученных значений емкости монослоя $a_{m}$, можно сделать вывод о том, что наилучшие сорбционные свойства фаза МУНТ по теории БЭТ проявляет к ацетону. Для этанола же наблюдается обратная зависимость - с увеличением массы фазы трубок чувствительность микровзвешивания его паров снижается. Наибольшую чувствительность микровзвешивания фазы карбоксилированных 
МУНТ с малыми массами проявляют к парам веществ с потенциально наибольшей вероятностью взаимодействия со всеми возможными центрами сорбции. Аномально высокое сродство фаз сорбента к парам фенола подтверждает ранее неоднократно установленную тенденцию сорбции и самосорбции паров фенола на пленках и фазах разной природы (полимерные, био-, природные, с хемореагентами) [13].

Для оценки эксплуатационных свойств фазы МУНТ-соон, как модификатора газовых сенсоров, рассчитана массовая селективность микровзвешивания относительно паров воды $\left(S=\Delta F_{\operatorname{mad}} \Delta F_{\operatorname{man}}(\right.$ воды) $)$ при инжекционном вводе пробы паров. Установлено, что фаза МУНТ-соон массой 5.0 мкг проявляет селективность к парам амилацетата, хлороформа и бензола, a МУНТ-соон малой массы 2.0 мкг - к хлороформу, бензиламину, амилацетату, уксусной и масляной кислотам (рис. 4). Это значит, что при равных условиях и концентрациях, пропорциональных давлению насыщенного пара для каждого вещества при температуре эксперимента, по откликам пьезосенсоров с указанными фазами можно детектировать присутствие этих соединений на фоне воды.

При различной массе фазы МУНТ. соон изменяется их селективность по отношению к насыщенным парам веществ. Следовательно, варьируя массу покрытия можно изменить его селективность микровзвешивания паров только за счет пространственных ограничений сорбции и особенностей оценки массы сорбата, при этом природа покрытия не меняется.

Для установления влияния природы и строения сорбтивов на эффективность
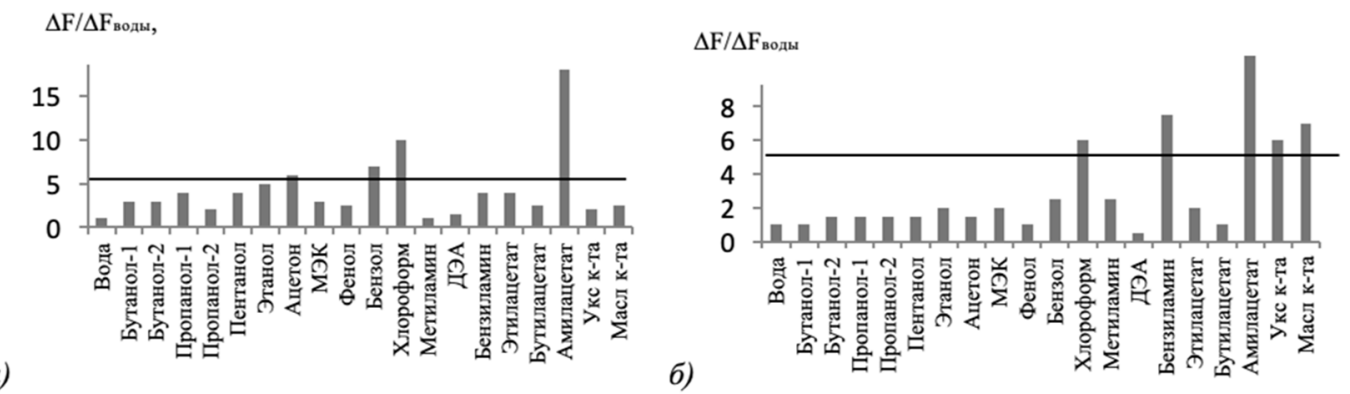

Рис. 4. Массовая селективность $(S)$ микровзвешивания паров относительно паров воды при инжекционном вводе в закрытую ячейку детектирования для пьезовесов с фазой углеродных нанотрубокмассой 5,0 мкг (a) и 2.0 мкг (б).

Fig. 4. Mass selectivity $(S)$ of microweighing of vapours relative to water vapour during injection into a closed detection cell for piezo balances with a phase of carbon nanotubes with a mass of $5.0 \mu \mathrm{g}(a)$ and $2.0 \mu \mathrm{g}(b)$.

a)

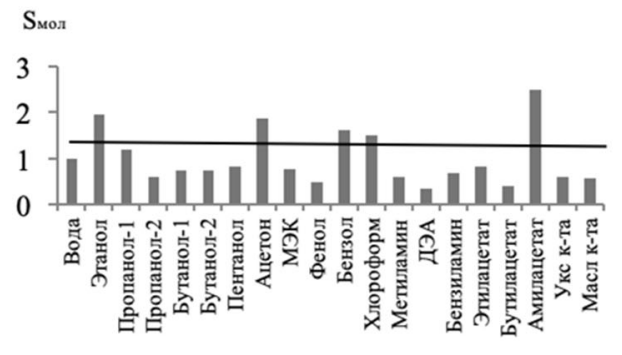

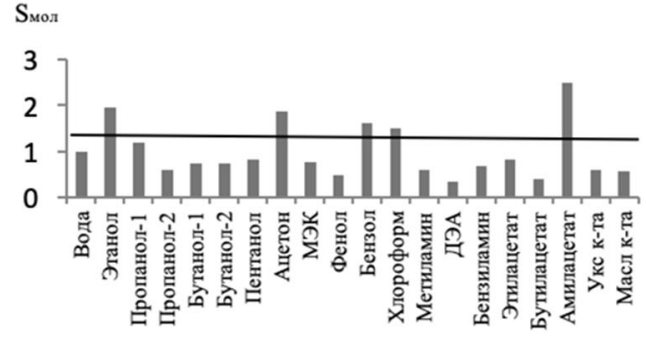

б)

Рис. 5. Молярная селективность микровзвешивания паров изученных веществ относительно воды при инжекционном вводе для разных масс сорбента: 5.0 мкг (a) и 2.0 мкг (б).

Fig. 5. Molar selectivity of microweighing of the vapours of the studied substances relative to water during injection for different masses of the sorbent: $5.0 \mu \mathrm{g}(a)$ and $2.0 \mu \mathrm{g}(b)$. 
Таблица 4. Расчетные качественные параметры для паров веществ при взвешивании одновременно несколькими пьезовесами с фазами МУНТ-соон разных масс

Table 4. Calculated quality parameters for vapours of substances when weighed simultaneously by several piezo balances with MWNT $_{\text {-сонн }}$ phases of different masses

\begin{tabular}{|l|c|c|c|c|c|c|}
\hline \multicolumn{1}{|c|}{ Вещества } & \multicolumn{2}{|c|}{ Чувствительность микровесов, Гц/рpm } & \multicolumn{3}{|c|}{ Расчетные параметры } \\
\hline Вода & 1.2 мкг & 2.0 мкг & 5.0 мкГ & $A(1 / 2)$ & $A(1 / 3)$ & $m(1 / 2 / 3)$ \\
\hline Бутанол-1 & 4.34 & - & 2.04 & - & 2.13 & 2.13 \\
\hline Бутанол-2 & 26.48 & - & 27.97 & - & 0.95 & 0.95 \\
\hline Пропанол-1 & 2.00 & 1.35 & - & 1.48 & - & 1.05 \\
\hline Пропанол-2 & - & 1.48 & 1.83 & 0.00 & - & 1.13 \\
\hline Пентанол-1 & 0.86 & 0.70 & 0.82 & 1.23 & 1.05 & 1.04 \\
\hline Ацетон & - & 6.91 & 8.57 & 1.36 & 1.10 & 1.09 \\
\hline Диэтиламин & 0.05 & 0.03 & - & 1.67 & - & 1.19 \\
\hline Этанол & 0.15 & 0.16 & 0.18 & 0.94 & 0.83 & 0.91 \\
\hline
\end{tabular}

сорбции оценивали молярная селективность $S_{\text {mol }}$ (рис. 5).

Покрытия малых масс позволяют фиксировать с максимальной избирательностью этанол, ацетон, амилацетат, амины, относящиеся к биомолекулам, а также бензол, хлороформ, фенол, как антропогенные вещества. При увеличении массы МУНТ_-соон принципиально молярная селективность фазы не изменяется.

Именно особенность сорбции и взвешивания с высокой чувствительностью локальной, ограниченной по площади и массе фазы сорбента, реализуемой в методе пьезокварцевого микровзвешивания, позволяют наблюдать различия в избирательности взвешивания паров веществ из смесей.

С учетом параметров линейности областей Генри и влиянии массы МУНТсоон на избирательность микровзвешивания паров, впервые установлена особенность изменения селективности на одном сорбенте к парам легко летучих органических соединений.

Однако, в реальных системах содержание летучих соединений может существенно изменяться друг относительно друга. Концентрационное влияние паров на результаты микровзвешивания смесей оценим по отношению констант Генри (таблица 4). При этом использовали прием повышения информативности детектирования веществ в смеси в инновационных аналитических системах на основе нескольких разноизбирательных и разночувствительных сенсоров «электронный нос». Постулировали одновременное применение пьезовесов с фазами МУНТ-соон разных масс и рассчитывали параметры эффективности сорбции $A_{\mathrm{i} j \mathrm{j}}$ и $m$, которые являются качественными характеристиками компонентов в смеси [14].

Из 7 расчетных параметров только 3 имеют идентификационные свойства. Амины (маркеры воспаления) идентифицируются по в присутствии других веществ по показателю $A(1 / 2)$. Ацетон относится к важнейшим биомаркерам состояния живых систем и диагностическим веществом, поэтому его идентификация в сложных смесях является приоритетной аналитической задачей. Следует отметить, что и появление смеси спиртов также надежно идентифицируется на фоне паров воды, ацетона, аминов. Среди спиртов возможно детектирование в смеси этанола (показатели А (1/2, $1 / 3)$ ).

\section{Заключение}

При малых концентрациях паров в пробе (ppm, ppb) для практически всех 
биомолекул возможно полуколичественное определение или констатация устойчивого изменения их концентрации. С учетом того, что при разработке аналитических систем с применением метода пьезокварцевого микровзвешивания стараются минимизировать пробоподготовку, этот факт выгодно отличает детектирование смесей паров и газов пьезосенсорами от других газовых сенсоров. При-

\section{Список литературы}

1. Mcginley C.M., Mcginley M.A. Air \& Waste Management Association Specialty Conference: Odors and Air Emissions. Hartford. 2006. pp. 9-12.

2. Кучменко Т.А. Химические сенсоры на основе пьезокварцевых микровесов. В монографии Проблемы аналитической химии. Под ред. Ю.Г. Власова. 2011. Т. 14. С.127202.

3. Корнев А.С. // Российский химический журнал. 2011. Т. 112. № 6. С. 94-101.

4. Васильев А.А., Павленко Р.А., Севастьянов В.А. // РЖ 19БД. 2008. № 15. С. 53.

5. Шогенов, Ю.Х., Кучменко, Т.А., Гражулене С.С., Редькин А.Н. // Журнал аналитической химии. 2012. Т. 67. № 1. С. 12-18.

6. Kuchmenko T., Umarkhanov R., Lvova L. // Sensors and Actuators, B: Chemical, 2020. Vol. 322. https://doi.org/10.1016/j.snb.2020.128585 менение нескольких однотипных сенсоров с модификаторами разных масс позволяет существенно расширить информативность анализа. Новым решением в газовой сенсорике является создание возможности идентификации в смесях отдельных паров без разделения при отсутствии селективного отклика.

7. Rajneesh M., Meetu B., Manmeet K., Kailasa G. et al. // BARC Newslett. 2009. No 297. pp. 240-245.

8. Кучменко Т.А., Умарханов Р.У. // Журнал аналитической химии. 2013. Т. 68. № 4. C. $397-405$.

9. Obirai Joseph C., Hunter Gary, Dutta Prabir K. // Sens. and Actuators. B. 2008. Vol. 134. No 2. pp. 640-646.

10.Кучменко Т.А., Умарханов Р.У., Кочетова Ж.Ю., Бельских Н.В. // Журнал аналитической химии. 2012. Т. 67. № 11. С. 1032.

11.Кучменко Т.А. Инновационные решения в аналитическом контроле. Воронеж. ВГТА. 2009. $252 \mathrm{c}$.

12.Кучменко Т.А., Сельманщук В.А. Патент РФ. № 2327984. 2008.

13.Kuchmenko T.A., Korenman Ya.I., Trivunac K.V., Rajakovič L.V. // J. of Analyt. Chem. 1999. Vol. 54. No 2. pp. 161-165.

14. Кучменко Т.А., Шуба А.А., Бельских Н.В. // Аналитика и контроль. 2012. Т. 16. № 2. C. 151-161.

\title{
Study of sorption properties of carboxylated carbon nanotubes on a baw-type piezo microbalance
}

\author{
(C) 2021 Kuchmenko T.A. ${ }^{1}$, Umarkhanov R.U. ${ }^{1,2}$, Cornejo Tueros H.B. ${ }^{3}$ \\ ${ }^{l}$ Voronezh State University of Engineering Technologies, Voronezh \\ ${ }^{2} \mathrm{OOO}$ "Sensorica - New Technologies", Voronezh \\ ${ }^{3}$ Universidad Continental, Huancayo, Peru
}

\begin{abstract}
The features of the sorption of vapours of individual highly volatile organic compounds of various classes on the phases of carboxylated carbon nanotubes $\left(\mathrm{MWNT}_{- \text {соoн }}\right)$. The peculiarity of the study was the use of a sorption phase of small masses (from 1 to $5 \mu \mathrm{g}$ ) and direct weighing of adsorbates of vapours of substances at any moment of sorption by highly sensitive piezo balances with a sensitivity of up to $10^{-12} \mathrm{~g}$. The dependence of the efficiency of sorption by the phase from MWNT -соон $_{\text {to }}$ vapours of the selected compounds (alcohols, ketones, acids, arenes) on the mass of the applied phase on a limited surface area. This approach to the formation of a layer of tubes allows one to obtain a surface and porosity of different structure, which determines the selectivity of vapour sorption. Calculations of sorption isotherms of compounds, allowing either to fix them highly selectively in a mixture or to estimate the change in concentration are presented. It was found that for the same sorbtive, the shape of the sorption isotherm on phases of different masses changes from linear to S-
\end{abstract}


shaped. Therefore, it is impossible to describe the curves with a single theory. The maximum capacity of the monolayer to acetone molecules and the minimum capacity to phenol vapours were established. Carboxylated nanotubes absorb aliphatic alcohols of normal and isomeric structure in different ways, butyl and pentyl alcohols are distinguished by the sorption characteristics. Mass-sensitive piezoelectric sensors with MWNT $_{\text {-соон }}$ of different masses are recommended as measuring elements for gas analysers and systems for the integral assessment of complex mixtures of compounds of low concentrations with the "electronic nose" methodology. The application in one array of sensors with MWNT $_{\text {-сон }}$ increases the selectivity of the detection of components in the mixture at the level of microconcentrations without separation.

Keywords: sorption, carbon nanotubes, organic biomolecules, sensors, electronic nose, analysis, microconcentrations.

\section{References}

1. Mcginley C.M., Mcginley M.A., Air \& Waste Management Association Specialty Conference: Odors and Air Emissions, Hartford, 2006, pp. 9-12.

2. Kuchmenko T.A. Himicheskie sensory na osnove p'ezokvarcevyh mikrovesov, V monografii Problemy analiticheskoj himii, Pod red. Ju.G. Vlasova, 2011, Vol. 14, pp. 127-202.

3. Kornev A.S., Rossijskij himicheskij zhurnal, 2011, Vol. 112, No 6, pp. 94-101.

4. Vasil'ev A.A., Pavlenko R.A., Sevast'janov V.A., RZh 19BD, 2008, No 15, pp. 53.

5. Shogenov Ju.H., Kuchmenko T.A., Grazhulene S.S., Red'kin A.N., Zhurnal analiticheskoj himii, 2012, Vol. 67, No 1, pp. 12-18.

6. Kuchmenko T., Umarkhanov R., Lvova L., Sensors and Actuators, B: Chemical, 2020, Vol. 322. https://doi.org/10.1016/j.snb.2020.128585

7. Rajneesh M., Meetu B., Manmeet K., Kailasa G. et al., BARC Newslett, 2009, No 297, pp. 240-245.

Кучменко Татьяна Анатольевна - д.х.н., профессор, профессор РАН, заведующая кафедрой физической и аналитической химии ВГУИТ, Воронеж

Умарханов Руслан Умарханович - к.х.н., доцент кафедры физической и аналитической химии ВГУИТ, директор ООО «Сенсорика Новые Технологии», Воронеж

Корнехо Туэрос Х.В. - к.т.н., магистр процессов энергосбережения в химических, нефтехимических и биотехнологических технологиях; доцент Континентального университета, Уанкайо, Хунин, Перу
8. Kuchmenko T.A., Umarhanov R.U., Zhurnal analiticheskoj himii, 2013, Vol. 68, No 4, pp. 397-405.

9. Obirai Joseph C., Hunter Gary, Dutta Prabir K., Sens. and Actuators. B, 2008, Vol. 134, No 2, pp. 640-646.

10. Kuchmenko T.A., Umarhanov R.U., KochetovaZh.Ju., Bel'skih N.V., Zhurnal analiticheskoj himii, 2012, Vol. 67, No 11, pp. 1032.

11. Kuchmenko T.A. Innovacionnye reshenija $\mathrm{v}$ analiticheskom kontrole, Voronezh, VGTA, $2009,252 \mathrm{p}$.

12. Kuchmenko T.A., Selmanshhuk V.A. Patent RF, No 2327984, 2008.

13. Kuchmenko T.A., KorenmanYa.I., Trivunac K.V., Rajakovič L.V., J. of Analyt. Chem., 1999, Vol. 54, No 2, pp. 161-165.

14. Kuchmenko T.A., Shuba A.A., Bel'skih N.V., Analitika i kontrol', 2012, Vol. 16, No 2, pp. 151-161.

Kuchmenko Tatyana A. - Doctor of Chemistry, Professor of the Russian Academy of Sciences, Head of the Department of Physical and Analytical Chemistry of VSUIT, Voronezh, Email: tak1907@mail.ru

Umarkhanov Ruslan U. - Candidate of Chemical Sciences, Associate Professor of the Department of Physical and Analytical Chemistry of VSUIT, Director of Sensorika - New Technologies LLC, Voronezh, E-mail: rus270487@mail.ru

Cornejo Tueros J.V. - PhD. in Philosophy with a major in Engineering Sciences. Master in Energy Resource Saving Processes in Chemical, Petrochemical and Biotechnology Technology. Docent in Continental University: Huancayo, Junin, Email: jcornejo@yandex.ru 